DOI:10.2151/jmsj.87.593

\title{
Changes in Cloud Optical Thickness and Cloud Drop Size Associated with Precipitation Measured with TRMM Satellite
}

\author{
Takahisa KOBAYASHI and Kazuhiko MASUDA
}

Meteorological Research Institute, Tsukuba, Japan

(Manuscript received 25 June 2008, in final form 9 March 2009)

\begin{abstract}
We derived rain rate, cloud optical thickness and the effective radius in water clouds by a combined use of the Precipitation Radar and the Visible and Infrared Scanner onboard the Tropical Rainfall Measuring Mission. The derived data were used to study how cloud optical thickness relates to precipitation. In particular, we focused on the changes in cloud optical thickness resulted from changes in the size distributions of cloud droplets associated with precipitation. There were considerable scatter between cloud optical thickness and rain rate on a global scale. However, cloud optical thickness was found to increase with rain rate on average. The tendency to increase was mostly due to increases in liquid water path and depended on rain rate. For strong rain, relatively small increases in the optical thickness with rain rate were observed. Whereas, for weak rain, larger increases with rain rate were found, which is related to considerable changes in liquid water path and in the effective radius of cloud droplets. To study the effects of drop size variation, the relationships between cloud optical thickness and rain rate for same values of liquid water path were analyzed. Results show that there were no significant dependences of cloud optical thickness on rain rate for strong rain. For weak rain, cloud optical thickness was found to decrease with rain rate. In particular, significant differences of optical thickness were found between nonprecipitating clouds and precipitating clouds: smaller cloud optical thickness was observed for precipitating clouds. Dispersion of cloud drop size was found in the rain formation process, which may relate to changes in the shape of drop size spectra and leads to the decreases in the cloud optical thickness for precipitating clouds.
\end{abstract}

\section{Introduction}

The cloud feedback problem is one of the largest uncertainties in climate studies (Stephens 2005) because cloud formation and dissipation are complicated processes. Clouds have mutual relations to aerosols and precipitation. Increases in aerosol concentrations result in a decreased drop size and modify the cloud radiative forcing, which is known as the 'first indirect effect' (Twomey 1974; Breon et al. 2002). The interactions between aerosols and clouds have been studied extensively using numerical models and observations with airborne sensors (e.g., Kuba et al. 2003; Asano et al. 1995) and

Corresponding author: Takahisa Kobayashi, Meteorological Research Institute, 1-1, Nagamine, Tsukuba, Ibaraki 305-0052, Japan.

E-mail: kobay@mri-jma.go.jp

(C) 2009, Meteorological Society of Japan space-borne solar and infrared radiometers (Kobayashi and Masuda 2008; Coakley and Bernstein 1987). Decreased drop size may also suppress precipitation, which is known as the 'second indirect effect' (Albrecht 1989; Rosenfeld 2000). Precipitation is generated from cloud drops by condensation and coalescence, which in turn generates cloud drops by breakup (Kobayashi and Adachi 2001), and removes cloud drops and controls cloud amount. A study on clouds-precipitation interaction is, therefore, critical to improve our understanding of the cloud feedback problem. Despite extensive studies on cloud-precipitation interactions (e.g., vanZanten et al. 2005), our understanding is very limited because of their complex nature.

A recent study suggested that there exist significant differences of the effective radius $\left(r_{e}\right)$ of cloud drops between non-precipitating clouds (NPC) and precipitating clouds (PRC) (Kobayashi 2007). The 
differences are associated with the fact that cloud drops grow to raindrops quickly when they exceed the critical radius $\left(r_{c}\right)$. This suggests that cloud optical thickness $(\tau)$ can be expected to change at $r_{e}$ around $r_{c}$ because $\tau$ is closely related to $r_{e}$. If liquid water content is conserved in the conversion process from cloud droplets to rain drops, cloud optical thickness is expected to decrease for PRC comparing with that for NPC associated with the increases in $r_{e}$. However, it is difficult to find the differences in $\tau$ between NPC and PRC, because liquid water contents increase significantly when the effective radius exceeds $r_{e} \sim 15 \mu \mathrm{m} \sim r_{c}$ (Gerber 1996), which compensates the decreases in $\tau$ arises from increased $r_{e}$.

Cloud optical thickness is primarily determined by liquid water content and secondarily by $r_{e}$. However, dependence of $\tau$ on the effective radius cannot be neglected. A small decrease in $r_{e}$ by $2 \mu \mathrm{m}$ could offset the warming effect of doubling the $\mathrm{CO}_{2}$ (Slingo 1990). Liu and Daum $(2000,2002)$ showed that increases in $r_{e}$ are associated with the broadening of the size distribution of cloud droplets from observations, which reduces the indirect effects of aerosols. The shape of the cloud droplet spectrum is modified by number of cloud droplets and cloud concentration nuclei (Takeda and Kuba 1982) and affects the indirect effects of aerosols significantly (Lohmann and Feichter 2005). It is, therefore, important to study how the size distribution of cloud droplets changes associated with precipitation and affects cloud optical thickness. In particular, broadening in the conversion process is important because the broadening were most closely associated with drizzle drops (Hudson and Yum 1997).

Here, we will examine the variation of cloud optical thickness in the auto conversion process in terms of the cloud drop size distribution for water clouds. In particular, understanding of the physical processes in low marine stratocumulus clouds is important because it has strong negative feedbacks and small changes in the amount could offset the warming effects resulting from $\mathrm{CO}_{2}$ doubling (Albrecht 1989; Randall et al. 1984).

\section{Satellite data}

The Tropical Rainfall Measuring Mission (TRMM) satellite primarily intends to measure temporal and spatial variations of precipitation (Kummerow et al. 2000). The TRMM has been continuously monitoring precipitation since the launch on November, 1997 and has five sensors, including Precipitating Radar (PR). The PR is a unique space borne sensor used to measure the three-dimensional rain structure with a horizontal resolution of $5 \mathrm{~km}$ at nadir and a swath of $215 \mathrm{~km}$. The vertical resolution is $125 \mathrm{~m}$. The TRMM is also equipped with a Visible and Infrared Scanner (VIRS) for measuring clouds, as well as the sea surface temperature and aerosols. The VIRS has five channels and measures visible and infrared radiance with a horizontal resolution of $2.4 \mathrm{~km}$ at nadir and a swath of $830 \mathrm{~km}$. Both sensors sample almost simultaneously and with similar spatial resolutions. Consequently, combined use of the PR and VIRS is well suited for studies of cloud-precipitation interactions. The orbit has an inclination of $35^{\circ}$ and the observed area is from $-35^{\circ}$ to $+35^{\circ}$ in latitude and $0^{\circ}$ to $360^{\circ}$ in longitude. We selected the VIRS data for which the center position of the PR is within the footprint of the VIRS and made match-up datasets from data for 11 days in December, 2002 and 10 days in June, 2003. The swath of the VIRS is wider than that of the PR. The VIRS data extending beyond the swath of the PR were excluded. Ultimately, we generated two global-segmented datasets, each with data for 10 or 11 days. One segment box has a $0.1^{\circ} \times 0.1^{\circ}$ latitude-longitude spatial resolution. Data exist for about 4 5 pixels in each grid box. The pixel for precipitating at the highest rain rate or for the highest reflection at Ch1 $(0.63 \mu \mathrm{m})$ when no precipitating pixels occur in a box was selected. Horizontally inhomogeneous clouds and cirrus clouds lead to some error (Kobayashi 1988; Kobayashi 1993; Han et al. 1994). In the analysis, pixels for which the brightness temperature at $\mathrm{Ch} 4(10.8 \mu \mathrm{m})$ of VIRS ranged from 273 to $290 \mathrm{~K}$ and the brightness temperature difference between $\mathrm{Ch} 4$ and $\mathrm{Ch} 5(12 \mu \mathrm{m})$ was less than $1 \mathrm{~K}$ were furthermore selected to remove erroneous data of optically thin, cold clouds and sub-pixel clouds (Rosenfeld and Gutman 1994).

\section{Method}

Cloud optical thickness and the effective radius can be estimated from space-borne measurements of radiances at two wavelengths based on the differences in water absorbing characteristics, like $0.75 \mu \mathrm{m}$ and $2.16 \mu \mathrm{m}$ (Nakajima and King 1990; Han et al. 1994) or more accurately by $0.64 \mu \mathrm{m}$ and $3.75 \mu \mathrm{m}$ (Nakajima and Nakajima 1995). Here, the reflected radiances at $\mathrm{Ch} 1(0.63 \mu \mathrm{m})$ and $\mathrm{Ch} 3$ $(3.75 \mu \mathrm{m})$ measured with the VIRS were used to de- 
rive the optical thickness and the effective radius of cloud droplets near the cloud tops (Kobayashi 2007). The effective radius is defined as follows.

$$
\operatorname{Re}=\frac{\int r^{3} N(r) d r}{\int r^{2} N(r) d r},
$$

where, $N(r)$ is drop size distribution and $r$ is radius of droplets. The retrieval method is based on the difference of water absorbing characteristics between solar reflectance at $\mathrm{Ch} 1$ and $\mathrm{Ch} 3$. The size distribution of cloud droplets is assumed to be the lognormal function as:

$$
N(r)=\frac{N_{0}}{\sqrt{2 \pi} \sigma r} \exp \left[-\left(\log r-\log r_{0}\right)^{2} / 2 \sigma^{2}\right] .
$$

Here, $r_{0}$ is the mode radius and the variance $\sigma$ is assumed to be 0.35 (Nakajima and King 1990). The phase function is calculated by Mie theory assuming spherical shape of water droplets. Bidirectional reflections at the top of atmosphere are calculated for various values of $r_{e}$ and $\tau$ by using radiative transfer model.

The radiance at $\mathrm{Ch} 3$ includes contributions of thermal emissions from the atmosphere and ground surface. The undesired thermal emissions from the cloud tops were removed from the measured radiance at $\mathrm{Ch} 3$. The cloud top height was determined from radiance at $\mathrm{Ch} 4(10.8 \mu \mathrm{m})$ using LOWTRAN-7 (Kneizys 1988) assuming the tropical model for the atmosphere above the cloud top. This assumption leads to some error in the derived $r_{e}$. However, a difference of $4 \mathrm{~K}$ between the model and the actual temperature profile causes an error of less than $0.7 \mu \mathrm{m}$ in the retrieved $r_{e}$ (Han et al. 1994; Kawamoto et al. 2001). Use of the midlatitude summer model for the atmosphere above the cloud top instead of the tropical model results in a difference of $0.8 \mu \mathrm{m}$ in the mean $r_{e}$. Since we applied the method to limited regions of latitude, this error is not serious. We ignored the thermal emission from the ground surface because we examined optically thick clouds (King 1987).

\section{Results}

Figure 1 shows the relationships between mean cloud optical thickness and rain rate for data from $0.1^{\circ} \times 0.1^{\circ}$ latitude/longitude grids (dotted line) Data from $0.5 \times 0.5^{\circ}$ grids are also plotted for comparison (solid line). Although there are large standard deviations of $\tau$ (vertical bars, upper: $0.1^{\circ} \times 0.1^{\circ}$, lower: $\left.0.5^{\circ} \times 0.5^{\circ}\right)$, cloud optical thick-

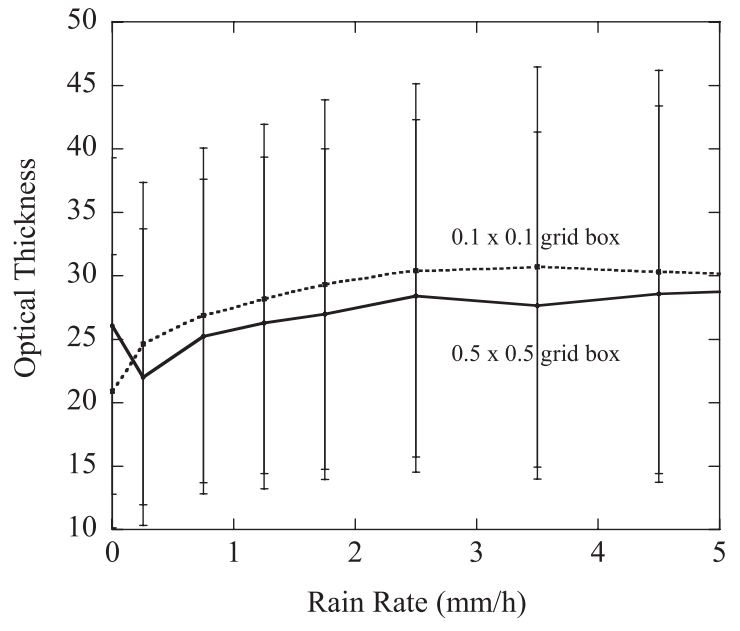

Fig. 1. Dependence of cloud optical thickness on rain rate for data from $0.1^{\circ} \times 0.1^{\circ}$ latitude/longitude grid box (dotted line) and $0.5^{\circ} \times 0.5^{\circ}$ grid box (solid line). Vertical bars are standard deviations of $\tau$ (upper: $0.1^{\circ} \times 0.1^{\circ}$, lower: $0.5^{\circ} \times 0.5^{\circ}$ ).

ness clearly tends to increase with rain rate for weak rain and tends to be constant and saturated for strong precipitation. Large error bars may interrupt reader's understanding, therefore we omitted error bars for other figures. Sharp increases in $\tau$ are observed between NPC (rain rate $=0$ ) and PRC for a segment box of $0.1^{\circ} \times 0.1^{\circ}$ which contains only $3-5$ pixels. For a segment box of $0.5^{\circ} \times 0.5^{\circ}$, however, cloud optical thickness is relatively large for NPC. Cloud optical thickness decreases in the conversion process from NPC to PRC with rain rate of $0.4 \mathrm{~mm} / \mathrm{h}$. Data exist for at least 100 pixels in each grid box of $0.5^{\circ} \times 0.5^{\circ}$. When no precipitating pixels occur in a box, the highest reflection at Ch1 was selected as a grid data. Consequently, optically thicker clouds were selected for $0.5^{\circ} \times 0.5^{\circ}$ grid box than those for $0.1^{\circ} \times 0.1^{\circ}$ grid. The decreases in $\tau$ found for $0.5^{\circ} \times 0.5^{\circ}$ grid data may be, therefore, artifact. However, measured non-precipitating clouds from $0.5^{\circ} \times 0.5^{\circ}$ grid box more likely represent NPC that grows to PRC than those from $0.1^{\circ} \times 0.1^{\circ}$ grid box, because more vigorous clouds produce precipitation. Thus, the decrease in $\tau$ may really occur in the conversion process from cloud droplets to raindrops. In the onset of precipitation, number of cloud droplets likely decreases in the conversion process associated with rapid growth by collision and removal of cloud droplets by drizzle. The de- 


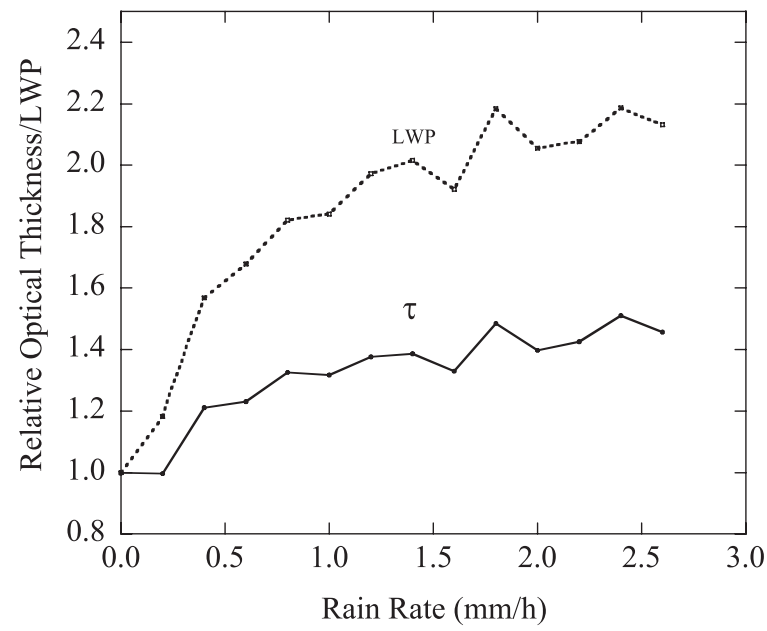

Fig. 2. Variations of mean cloud optical thickness (solid line) and liquid water path (dotted line) versus rain rate.

creased droplets concentration results in the decreases in cloud optical thickness for PRC. These effects are critical to examine the second indirect effect in which increased aerosols result in suppression of precipitation and affect the lifetime of clouds.

Cloud optical thickness is determined primarily by liquid water path (LWP) and secondarily by drop size distributions as mentioned earlier. Size of cloud droplets changes by factor of 1 or 2 , whereas LWP ranges over factors of 2 or 3 and primarily determines $\tau$. Liquid water path can be derived as a secondarily variable from primary observables, $\tau$ and $r_{e}$ approximated as

$$
\mathrm{LWP} \approx \frac{2}{3} \tau \rho \mathrm{Re},
$$

where, $\rho$ is the density of liquid water. Figure 2 shows variations of $\tau$ and LWP with rain rate. Relative values of LWP and $\tau$ to those at rain rate $=0$ are plotted. The relative values of LWP increase more significantly than those of $\tau$ do. In particular for rain rate ranging from 0 to $1 \mathrm{~mm} / \mathrm{h}$, increases in $\tau$ are slower than LWP. Cloud optical thickness is linearly related to LWP for a fixed drop size distribution. Thus, the different increasing tendencies between $\tau$ and LWP suggest that there exist changes in $r_{e}$ and likely in the spectral shape of the size distributions of cloud droplets with rain rate. In particular, large differences are found for degree to which $\tau$ and LWP increase with rain rate in the

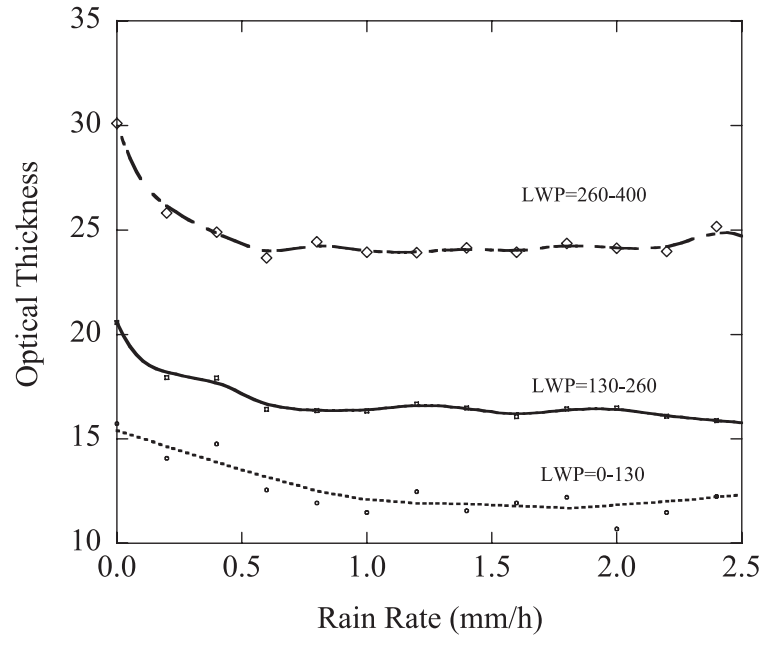

Fig. 3. Mean cloud optical thickness versus rain rate for liquid water content ranging from 0 to 130,130 to 260 , and 260 to $400 \mathrm{~g} / \mathrm{m}^{2}$.

conversion process from cloud droplets (NPC) to raindrops (PRC). This indicates that there are significant differences of the size distributions that are active in the visible optics region between NPC and PRC.

In the present study, we intend to examine the effects of precipitation on $\tau$ in terms of the size of cloud droplets. We, therefore, need to remove the contribution of LWP to $\tau$. To study the effects of drop size on $\tau$, we examined the relationships between $\tau$ and rain rate for fixed values of LWP. We averaged $\tau$ for three values of LWP ranging from 0 to 130 , from 130 to 260 and from 260 to $400 \mathrm{~g} / \mathrm{m}^{2}$ (Fig. 3). Cloud optical thickness tends to decrease with rain rate, which is in contrast to the increasing tendencies of $\tau$ with rain rate as shown in Fig. 1. The decreasing tendencies of $\tau$ with rain rate for fixed values of LWP shown in Fig. 3 are mostly due to the change in the size distributions of cloud droplets. For stronger rain, cloud optical thickness is almost constant as in Fig. 1, suggesting that no significant changes in the corresponding size distributions occur within the size range detected by visible optics.

Figure 4 shows the dependence of $r_{e}$ on rain rate for three ranges of LWP as in Fig. 3. The effective radius is almost constant for rain rate larger than $1 \mathrm{~mm} / \mathrm{h}$, corresponding to the small variations of the ratio of $\tau$ to LWP with rain rate as shown in Fig. 3. For weak rain, $r_{e}$ increases with rain rate, corresponding to the decrease in $\tau$ with rain rate as 


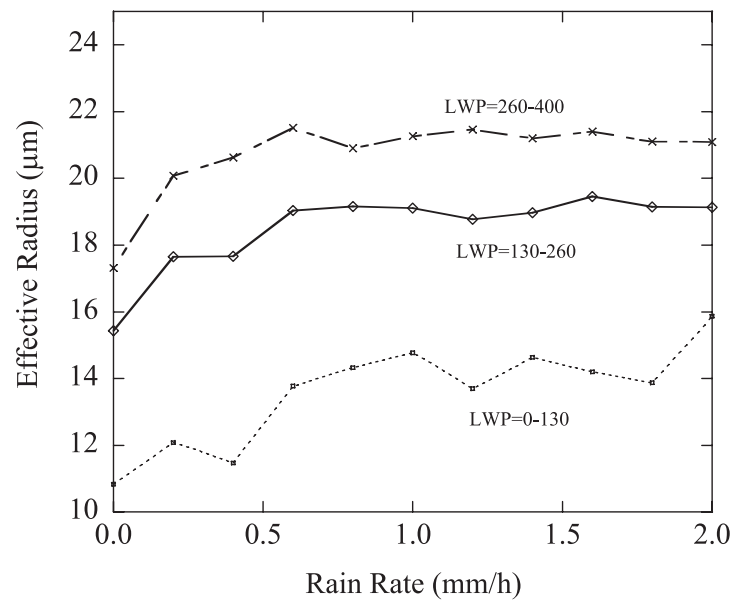

Fig. 4. Mean derived effective radius versus rain rate for various values of LWP as in Fig. 3.

shown in Fig. 3. Previous study reported significant increases in $r_{e}$ for PRC comparing with NPC (Kobayashi 2007). Figure 4 shows that the significant differences in $r_{e}$ between NPC and PRC occur for any values of LWP.

The increases in $r_{e}$ with rain rate likely occur associated with changes in the shape of the size distribution of cloud droplets. For NPC, most cloud droplets are smaller than $r_{c}$ and primarily grow by condensation. Whereas, for PRC, cloud droplets larger than $r_{c}$ primarily grow by coalescence. These different processes of growth possibly result in changes in the cloud drop size distributions between NPC and PRC. During drizzle formation, broadening of the drop spectra likely occurs (Feingold et al. 1997). The spectral broadening to larger size leads to increase in $r_{e}$ and decreases in $\tau$ assuming constant LWP. The spectral broadening, therefore, is a key factor to improve our understanding of cloudprecipitation interaction. It is needed to examine whether the spectral broadening occurs on a global scale or not. In the present study, however, we derived $\tau$ and $r_{e}$ by assuming the lognormal function with fixed value of $\sigma$ as 0.35 for the cloud drop spectra and cannot determine the variations of the spectral broadening explicitly. To estimate the dispersion of the cloud droplets size distribution, we have used the variations of the derived values of $r_{e}$ instead. The variation of the derived effective radius derived for pixel by pixel can be a measure of the dispersion of the averaged size distribution for a large area to some degree.

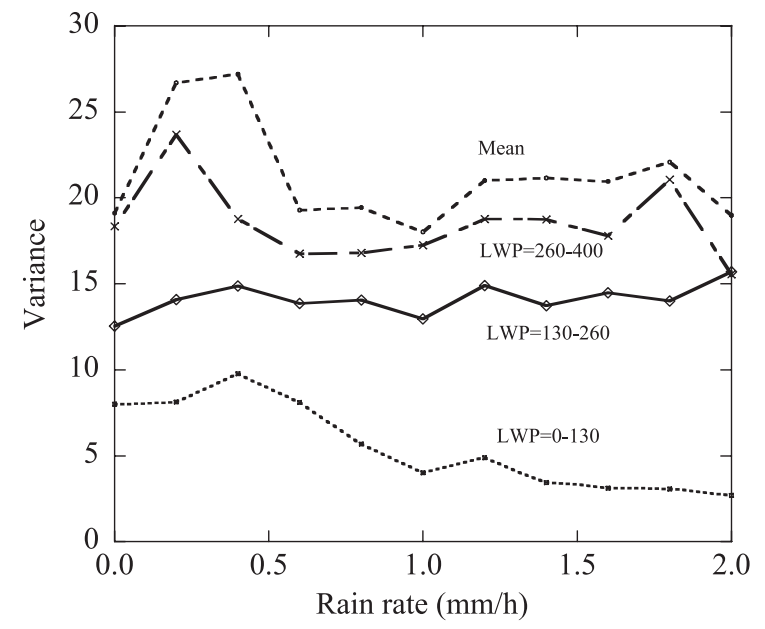

Fig. 5. Variances of the derived effective radius for various values of LWP.

Figure 5 shows the variances of $r_{e}$ as a function of rain rate for various values of LWP as in Fig. 3. Significant increases in the mean variances (dashed line) over whole values of LWP are found at weak rain rate. For large values of LWP, the increases are also found at weak rain rate. Whereas, no apparent peaks are found for small LWP. These features well correspond to the variation of $\tau$ with rain rate shown in Fig. 3. Vertical variations of the standard deviation of cloud droplet mean diameter are larger for higher altitude in which more drizzle and broadened drop size distribution are observed (Hudson and Yum 2001). The increases in the variance of $r_{e}$ shown in Fig. 5, are therefore thought to be associated with broadened size distribution.

Figure 6 shows average drop size distributions obtained from the derived effective radius over rain rate ranging from 0 to $0.3,0.5$ to 1 , and 3 to $4 \mathrm{~mm} /$ $\mathrm{h}$ as well as NPC. Normalized size distributions are plotted. The width of the size distribution is narrower for NPC than that for PRC. For PRC, the mode radius is larger and the width of the distributions is wider for stronger precipitation. For rain rate larger than a few $\mathrm{mm} / \mathrm{h}$, no significant changes in the size distributions appear, suggesting increases in large cloud droplets that are inactive in the visible optics region associated with strong precipitation. Differences of the normalized size distributions between NPC (solid lines) and PRC (dotted lines) are shown in Fig. 7 for LWP ranging from 0 to 130 and 260 to $400 \mathrm{~g} / \mathrm{m}^{2}$. For small value of LWP, slight differences are found. For larger LWP, however, broader shape of drop size distribution is 


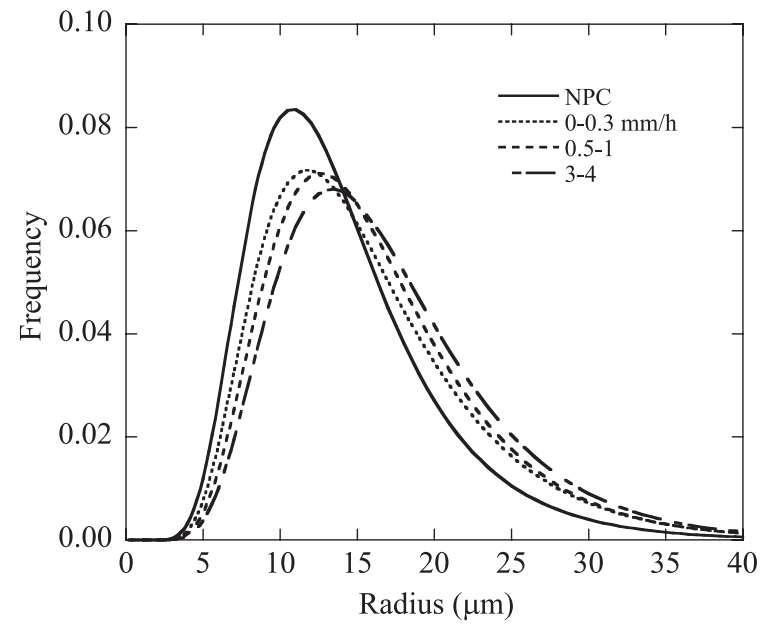

Fig. 6. Averaged cloud droplets size distributions calculated using derived effective radius for NPC and PRC with rain rate ranging from 0 to $0.3,0.5$ to 1 , and 3 to $4 \mathrm{~mm} / \mathrm{h}$.

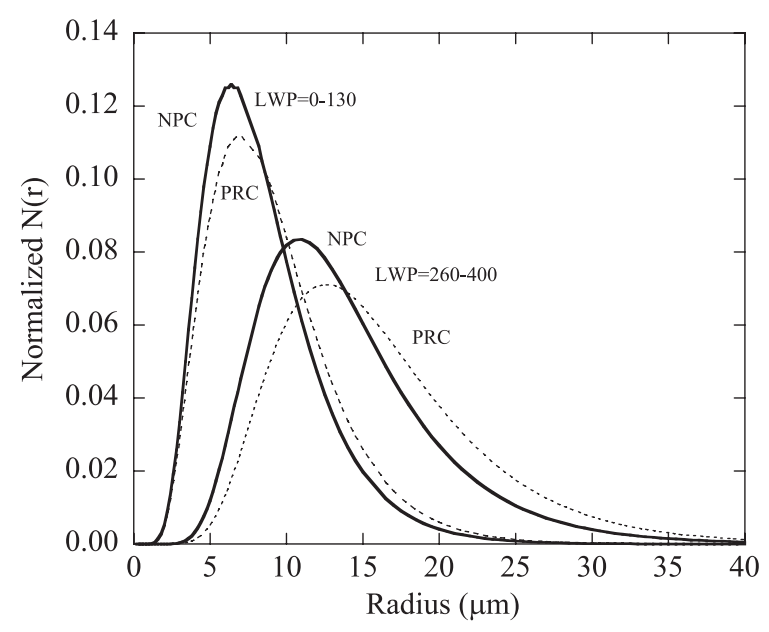

Fig. 7. Averaged cloud droplets size distributions calculated using derived effective radius for various values of LWP.

found for PRC, corresponding to the significant change in the variations shown in Fig. 5 .

Figure 8 shows relative values of cloud optical thickness calculated theoretically by using Mie theory from the averaged drop size distributions as a function of rain rate for various values of LWP. Observed optical thickness (Fig. 3) relative to that at rain rate $=0$ are also plotted (circles, crosses and triangles). Relative values of $\tau$ were calculated from the normalized size distributions so that they

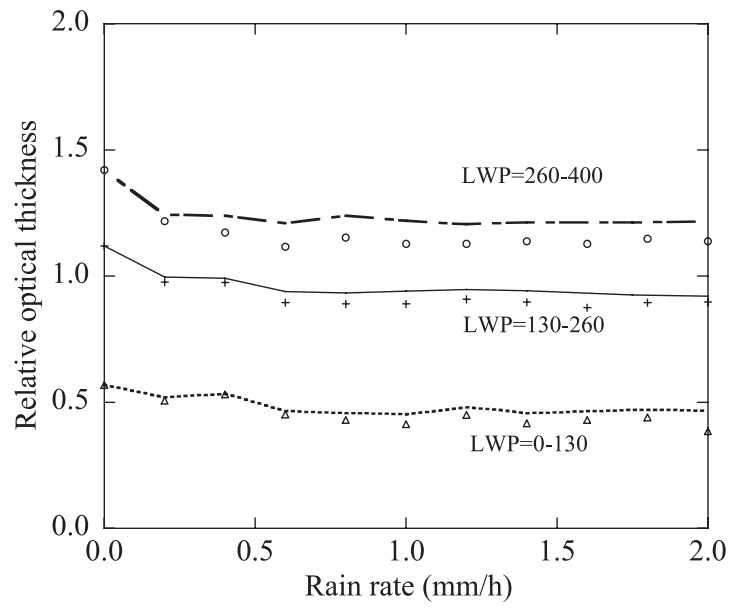

Fig. 8. Calculated cloud optical thickness from averaged cloud droplets size distributions for various values of LWP. Circles, crosses and triangles are observed optical thickness relative to those at rain rate $=0$ for each range of LWP.

were for the same liquid water content. Decreases in $\tau$ are clearly found in clouds with weak rain, which is in good agreement with the observations. Figure 8 suggests that the variations of cloud optical thickness with rain rate are closely related to changes in the shape of size distributions of cloud droplets.

\section{Conclusions}

Cloud optical thickness and the effective radius were derived from a combined use of the VIRS and the PR onboard the TRMM satellite to examine the effects of precipitation on the cloud properties. We focused on the effects of the size distributions of cloud droplets on cloud optical thickness associated with precipitation. Overall cloud optical thickness increases with rain rate for weak rain and is almost independent of rain rate for stronger rain than a few $\mathrm{mm} / \mathrm{h}$. The increase in cloud optical thickness was found to be primarily due to increases in LWP. To exclude the effects of increases in LWP on $\tau$, cloud optical thickness for fixed values of liquid water path was examined. Such derived cloud optical thickness for weak rain showed opposite dependence of rain rate for large values of LWP. Cloud optical thickness tended to decrease with rain rate and was larger for NPC than that for PRC. In particular for large values of LWP, difference of $\tau$ between NPC and PRC was 
significant. Dispersion of cloud drop size was found in the rain formation process, which may relate to changes in the shape of drop size spectra and leads to the decreases in the cloud optical thickness for precipitating clouds.

\section{Acknowledgements}

This study is partly supported by the Japan Aerospace Exploration Agency and by Grant-in Aids for Scientific Research No. 18540437, Japan Society for the Promotion of Science.

\section{References}

Albrecht, B. A., 1989: Aerosol, cloud microphysics, and fractional cloudiness, Science, 245, 1227-1230.

Asano, S., M. Shiobara, and A. Uchiyama, 1995: Estimation of cloud physical parameters from airborne spectral reflectance measurements for stratocumulus clouds, J. Atmos. Sci., 52, 3556-3576.

Breon, F. -M., D. Tanre, and S. Generoso, 2002: Aerosol effect on cloud droplet size monitored from satellite, Science, 295, 834-838.

Coakley, J. A. Jr, and R. L. Bernstein, 1987: Effect of ship-track effluents on cloud reflectivity, Science, 237, 1020-1022.

Feingold, G., R. Boers, B. Stevens, and W. R. Cotton, 1997: A modeling study of the effect of drizzle on cloud optical depth and susceptibility, J. Geophys. Res., 102, 13527-13534.

Gerber, H., 1996: Microphysics of marine stratocumulus clouds with two drizzle modes, J. Atmos. Sci., 53, 1649-1662.

Han, Q., Rossow, W. B., and A. A. Lasis, 1994: Nearglobal survey of effective droplet radii in liquid water clouds using ISCCP data, J. Climate, 7, 465-497.

Hudson, J. G., and S. S. Yum, 1997: Droplet spectral broadening in marine stratus, J. Atmos. Sci., 54, $2642-2654$.

Hudson, J. G., and S. S. Yum, 2001: Maritimecontinental drizzle contrasts in small cumuli, $J$. Atmos. Sci., 58, 915-926.

Kawamoto, K., T. Nakajima, and T. Y. Nakajima, 2001: Wide-area determination of cloud microphysics properties from NOAA AVHRR measurements for FIRE and ASTEX regions, J. Climate, 14, 2054-2068.

King, M. D., 1987: Determination of the scaled optical thickness of clouds from reflected solar radiation measurements, J. Atmos. Sci., 44, 1734-1751.

Kneizys, F. X., E. P. Shettle, L. W. Arbeu, J. H. Chetwynd, G. P. Andersen, W. O. Gallery, J. E. Selby, and S. A. Clough, 1988: Users guide to LOWTRAN-7. Air Force Geophysical Lab., Tech. Rep., AFGL-TR-88-0177.
Kobayashi, T., 1988: Parameterization of Reflectivity for Broken Cloud Fields. J. Atmos. Sci., 45, 30343045.

Kobayashi, T., 1993: Effects due to cloud geometry on biases in the albedo derived from radiance measurements, J. Climate, 6, 120-128.

Kobayashi, T., and A. Adachi, 2001: Measurements of raindrop breakup by using UHF wind profilers, Geophys. Res. Lett., 28, 4071-4074.

Kobayashi, T., 2007: Significant differences in the cloud droplets effective radius between nonprecipitating and precipitating clouds, Geophys. Res. Lett., 34, L15811, doi:10.1029/2007GL29606.

Kobayashi, T., and K. Masuda, 2008: Effects of precipitation on the relationships between cloud optical thickness and drop size derived from space-borne measurements, Geophys. Res. Lett. 35, L24809, doi:10.1029/2008GL036140.

Kuba, N., H. Iwabuchi, K. Maruyama, T. Hayasaka, T. Takeda, and Y. Fujiyoshi, 2003: Parameterization of the effect of cloud condensation nuclei on optical properties of a nonprecipitating water layer cloud, J. Meteor. Soc. Japan, 81, 393-414.

Kummerow, C., J. Simpson, O. Thiele, W. Barnes, A. T. C. Chang, E. Stocker, R. F. Adler, A. Hou, R. Kakar, F. Wentz, P. Ashcroft, T. Kozu, Y. Hong, K. Okamoto, T. Iguchi, H. Kuroiwa, E. Im, Z. Haddad, G. Huffman, B. Ferrier, W. S. Olson, E. Zipser, E. A. Smith, T. T. Wilheit, G. North, T. Krishnamurti, and K. Nakamura, 2000: The status of the Tropical Rainfall Measuring Mission (TRMM) after two years in orbit, J. Appl. Meteor., 39, 1965-1982.

Liu, Y., and P. H. Daum, 2000: Spectral dispersion of cloud droplets size distributions and the parameterization of cloud droplet effective radius, Geophys. Res. Lett., 27, 1903-1906.

Liu, Y., and P. H. Daum, 2002: Indirect warming effect from dispersion forcing, Nature, 419, 580-581.

Lohmann, U. G., and J. Feichter, 2005: Global indirect aerosol effects: a review, Atmos. Chem. Phys, 5, 715-737.

Nakajima, T., and M. D. King, 1990: Determination of the optical thickness and effective particle radius of clouds from reflected solar radiation measurements. Part I: Theory, J. Atmos. Sci., 47, 1878-1893.

Nakajima, T. Y., and T. Nakajima, 1995: Wide-area determination of cloud microphysics properties from NOAA AVHRR measurements for FIRE and ASTEX regions, J. Atmos. Sci., 52, 4043-4059.

Randall, D. A., J. A. Coakley, C. W. Fairall, R. A. Kropfli, and D. H. Lenschow, 1984: Outlook for research on subtropical marine stratiform clouds, Bull. Am. Meteor. Soc., 65, 1290-1301.

Rosenfeld, D., 2000: Suppression of rain and snow by urban and industrial air pollution, Science, 287, 1793-1796. 
Rosenfeld, D., and G. Gutman, 1994: Retrieving microphysical properties near tops of potential rain clouds by multispectral analysis of AVHRR data, Atmos. Res., 34, 259-283.

Slingo, A., 1990: Sensitivity of the Earth's radiation budget to changes in low clouds. Nature, 343, 49-51.

Stephens, G. L., 2005: Cloud feedbacks in the climate system: A critical review, J. Climate, 18, 237-273.

Takeda, T., and N. Kuba, 1982: Numerical study of the effect of $\mathrm{CCN}$ on the size distribution of cloud droplets. Part I. Cloud droplets in the stage of condensation growth. J. Meteor. Soc. Japan, 60, 978 993.

Twomey, S., 1974: Pollution and planetary albedo, Atmos. Environ., 8, 1251-1256.

VanZanten, M. C., B. Stevens, G. Vali, and D. H. Lenschow, 2005: Observation of drizzle in nocturna marine stratocumulus, J. Atmos. Sci., 62, 88-106. 